\title{
A Scoping Review on the Characteristics of Human Exposome Studies
}

\author{
Nadine Haddad ${ }^{1} \cdot$ Xanthi D. Andrianou $^{1} \cdot$ Konstantinos C. Makris $^{1}$ (D)
}

Published online: 28 November 2019

(C) The Author(s) 2019

\begin{abstract}
Embraced as a breaking through methodological framework, the exposome is accompanied by novel exposure assessment methods and data processing tools or models. However, systematic mapping of the landscape of exposome studies, including their characteristics, components, tools and language has not been done so far. We conducted a scoping review to answer the question: "Which main domains of the human exposome have been included in the literature and which metrics of exposure(s)/ outcome(s) have been used?" We performed a comprehensive search of human studies containing the word "exposom*" and published up to March 8, 2019. We screened 1133 records and 82 studies were included in the analysis. Most studies took place in Europe. Data analysis showed the non-systematic use of the exposome term. Most studies had a longitudinal design $(n=30$, $37 \%)$, were conducted on adults $(n=40,51 \%)$, and had a clearly defined health outcome in methodology $(n=48,61 \%)$. Omics tools, such as metabolomics were used in 38 studies (49\%), while environment-wide association analysis was used in 9 studies $(11 \%)$. Thirty-seven (48\%) studies included all three exposome domains (general external, specific external and internal) while $33(42 \%)$ studies included two. Despite the large number of environmental components that comprise each of the exposome domains, only a subset has been currently studied. An optimized consideration of the components from all exposome domains, as well as the standardization of the exposure and outcome assessment methods is warranted to advance the utility of the human exposome concept.
\end{abstract}

Keywords Cohorts $\cdot$ Exposome $\cdot$ Domains $\cdot$ EWAS $\cdot$ Omics $\cdot$ Environmental health $\cdot$ Personalized medicine $\cdot$ Trials

\section{Introduction}

Over the last decade, the human exposome, or simply the exposome has emerged as a novel research paradigm in epidemiology, biomedical, and environmental health sciences. Originally proposed by Dr. Chris Wild in 2005 [1], the exposome encompasses the totality of environmental exposures from conception onwards, complementing the genome.

This article is part of the Topical Collection on Human Health Effects of Environmental Pollution

Electronic supplementary material The online version of this article (https://doi.org/10.1007/s40726-019-00130-7) contains supplementary material, which is available to authorized users.

Konstantinos C. Makris

konstantinos.makris@cut.ac.cy

1 Water and Health Laboratory, Director, Cyprus International Institute for Environmental and Public Health, Faculty of Health Sciences, Cyprus University of Technology, Irinis 95, 3041 Limassol, Cyprus
Following the first definition, in 2012, three broad exposome domains, often overlapping with each other were also proposed by Dr. Wild to classify environmental exposures within the exposome. These domains are as follows: the general external (wider influential factors, such as social capital, urban-rural environment, and climate), the specific external (chemical contaminants, infectious agents, occupation and lifestyle, etc.) and the internal domain (metabolism, oxidative stress, aging, etc.) [2]. Growing attention is currently being paid to the role of the totality of environmental exposures and their endogenous response as it is imprinted across the lifespan in shaping disease risk and disease development ([3-5]).

In contrast to earlier epidemiological approaches that considered the reductionist concept of "one exposure-one outcome" associations at a time, the exposome goes one step further by examining the multitude of environmental exposures that dynamically evolve over time and space for an individual and populations. Thus the more informative the exposure assessment tool/metric used, the more accurate 
measurement of the exposome will be [6]. As such, novel methodologies and tools are currently considered for better assessment of the human exposome. These tools range from targeted biomonitoring and untargeted approaches using omics technologies (e.g., genomics, proteomics, transcriptomics, and metabolomics) to the use of personal samplers and wearable sensors. In light of the simultaneous consideration of multiple exposures in association studies with health outcomes, novel statistical and computational methods have emerged, such as those used in the environment-wide association study approach (EWAS), or the metabolome-wide association study (MWAS) approach that are often combined with the more classical genome-wide association study approach (GWAS) as well as other advanced statistical methods (e.g., Lasso, [7]).

The body of global literature on the exposome has been growing in the past years, yet with remarkable nuances given the embryonic nature of the concept [8]. Numerous reviews and commentaries/perspectives on the human exposome and its utility exist, either favoring or challenging its implementation [5, 6, 9-15]. Currently, exposome studies focus on either a health outcome, such as cancer $[16,17]$, diabetes [18], gastrointestinal diseases $([19,20]$, kidney stones [21], skin aging [22], Parkinson disease [23], reproductive health [24-27], or on various exposure(s)/outcome(s) metrics used in one or more domains of the exposome [28-33].

However, in order to advance the utility and societal impact of the exposome, it is crucial to improve our understanding of the methodological practices that have been used in primary human exposome studies. Towards this goal, we conducted a scoping review to (i) describe the existing exposome studies in terms of study participants, interventions, and outcomes; (ii) present the exposome domains and their corresponding groups of components in the selected studies; (iii) describe the variety of tools of exposure(s)/outcome(s) metrics and data discovery techniques used, and (iv) evaluate the overall methodological quality of the exposome studies.

\section{Methods}

A review protocol was prepared based on the Cochrane Handbook for Systematic Reviews of Intervention [34] and the Joanna Briggs methodology for scoping reviews [35]. Between March 1 and March 8, 2019, three electronic databases-Pubmed [36]; Scopus [37]; and bioRxiv, the pre-print server for Biology [38] - were searched for the term "exposom*". Additionally, the following four exposome websites: Human exposome project [39], HELIX [40], CIRCLE [41], HEALS [42], as well as the EU Community
Research and Development Information Service website (Cordis) [43], were reviewed using the same search string for publications that might have not been included in the electronic databases initially searched.

We included studies in English that described original research conducted on humans and if they contained the word "exposom*". Following deduplication of the records, we screened titles, abstracts, and main texts. We excluded (i) review papers or perspectives/commentaries/editorials and meta-analyses, (ii) studies conducted in animals or in vitro, (iii) due to non-relevance to the exposome concept and, (iv) studies containing the word "exposom*" in any part besides the main text. No time restriction was set to any of the search engines.

Retained articles and, when provided, their supplementary information material were reviewed by two independent researchers and tabulated data from each article were added in four ad hoc pre-designed Excel sheets. From each study, the information was initially recorded as a text then categorized when feasible to include:

i) Number of counts for the word exposom as a surrogate metric of the conscious intention of the authors to base their study on the exposome concept and by year of publication.

ii) P.I.C.O. table: populations; interventions; comparators, and outcomes

iii) Exposome domains and their specific components/variables following Wild's classification [2] were treated as a categorical variable (yes/no), specifying whether they were tackled or not in each study. Examples of grouped components included in a domain are shown below:

- Internal domain: intrinsic properties (such as body morphology), reproductive health (parity, gravidity, breastfeeding); medical outcome (medical history and existing medical condition); metabolic profiling; gene expression profiling and background characteristics present in every study, such as age, sex, and race.

- Specific external domain: air pollutants $\left(\mathrm{NO}_{\mathrm{x}}, \mathrm{NO}_{2}\right.$, $\mathrm{CO}$, benzene, metals), particulate matter (PM2.5, PM10, airborne pollen, dust), noise (residential noise, traffic noise), soil contaminants (concentrations of metal and other contaminants in soil), water contaminants (drinking water chemicals, water microbes), chemical contaminants (including pesticides and disinfection-byproducts), infectious agents (sexually transmitted infections, HIV/AIDS, etc.), lifestyle (such as smoking and alcohol consumption) as well as occupation. 
- General external domain: meteorology and climate (such as weather conditions, air temperature, humidity, season), natural and built environment (land cover, building density, street connectivity, vegetation), socio-economic status (including education), psychological and mental stress (life events, emotional/psychological issues, traumatic life events, separation/anxiety, childhood affection from parents, etc.), in addition to health programs and policies (healthcare infrastructure, food-access government programs, health promotion, and disease prevention programs).

In parallel, the methods employed for exposure and outcome assessment were categorized (yes/no) according to their use in each study. Assessment methods were as follows: self-reported exposure or outcome, use of secondary data (such as medical/hospital records, routinely collected data), environmental testing (for water, soil, or dust), use of personal/portable wearable device/sensors, use of satellite imaging and geospatial modelling, clinical assessment, and-omics platforms, such as metabolomics or genomics.

The lack of a gold standard in quality assessment covering all study designs [44], let alone the exposome studies, led us to conduct an exploratory quality assessment using the Effective Public Health Practice Project (EPHPP) quality tool [45]. The EPHPP tool rates the overall quality of a study according to six methodological components: selection bias, study design, confounder, blinding, data collection method, as well as withdrawal and dropout. Each component can be rated as weak, moderate or strong according to a set of defined questions. Studies are thereafter rated as "overall weak, overall moderate or overall strong" according to the number of "weak" rated components. For instance, a study is rated as: "overall strong" if none of the six components is rated as weak, "overall moderate" for one component rated as weak, and "overall weak" for two or more components rated as weak. It is noteworthy to mention that this quality assessment was exploratory in nature and not an integral part of the overall scoping review analysis.

Descriptive statistics using Excel pivot tables were conducted for all retained studies. The "exposom*" word count was treated as a continuous variable. On the other hand, frequencies and proportions were used for categorical variables, namely, study design, country of publication (considered as the country of the first author) participants' profile, interventions applied, types of outcomes, exposome domains, and the assessment methods. Later, the overall quality was described with respect to the rating components.

\section{Results}

\section{Description of the Selected Studies}

The search yielded a total of 1133 hits: 460 unique records in Pubmed, 573 in Scopus, 29 in bioRxiv, and 71 in the exposome websites. All the retrieved articles were merged into a single dataset with 682 duplicates. Thus, 452 records were initially retained. A first stage of screening titles and abstracts excluded 336 articles for not meeting eligibility criteria (as elaborated in caption of Fig.1). Additionally, 32 articles were excluded for not containing the word "exposom*" in text. Full-text screening excluded two more articles: one meta-analysis, and another one for demonstrating the applicability of heat maps using existing environmental and biomarker measurements. In effect, 82 articles were eventually retained for the scoping review (Fig. 1).

\section{Description of the Selected Articles}

Approximately a third of the retained exposome studies had a prospective longitudinal design $(n=30,37 \%)$, of which 26 were based on nine large population-based cohorts; the rest four longitudinal studies were relatively small in size, including between 6 and 378 subjects [46-49]. Out of the 26 studies, eleven were published as part of the Human Early-Life Exposome (HELIX) project using data from six European birth cohorts ([50-56]), and among these studies, four belonged to the Spanish INMA (INfancia y Medio Ambiente) [57-61]. Four studies (of the 26) were published as part of the Avon Longitudinal Study of Parents and Children (ALSPAC), a 20-year population-based cohort designed to determine the influence of environmental (physical and psychological) and genetic factors on the health status and development of the offspring. Three studies were based on the LIFE cohort, which follows $\sim 500$ couples from 16 US counties in Michigan and Texas across sensitive windows of human reproduction and development [62-64]. Additionally, a prospective study design for each of the following cohorts was recorded for the ENVIRONAGE birth cohort (Belgium) [65]; the "Lifestyle and environmental factors and their influence on Newborn Allergy risk" (LiNA) prospective motherchild cohort (Germany) [66]; the prenatal Kingston Allergy Birth Cohort (KABC) (Canada) [67]; and the Maternal-Infant Research on Environment Chemicals (MIREC) Study (Canada) [68]. Two studies were about the HERACLES (waste management) Greek cohort (Greece) $[69,70]$. One study followed participants from ALSPAC, ENVIRONAGE, INMA, Rhea (Greek cohort), 
Fig. 1 Flowchart of the study selection process. (a) Excluded items were overviews/ perspectives/commentary/ editorial $(n=215)$, not exposomebased meta-analysis $(n=3)$, studies on animal subjects $(n=22)$, description of laboratory methods $(n=19)$, conference or meeting notes $(n=17)$, description of a database or data tool $(n=15)$, application of statistical models $(n=10)$, cellular or in vitro studies $(n=8)$, exposome-funded project description $(n=5)$, presentation of a measurement tool $(n=5)$, studies on human tissues $(n=3)$, presentation of an R statistical package $(n=3)$, presentation of a website or search engine $(n=4)$, semantic studies $(n=2)$, studies presenting methods of environmental sampling $(n=3)$, studies not in English $(n=2)$

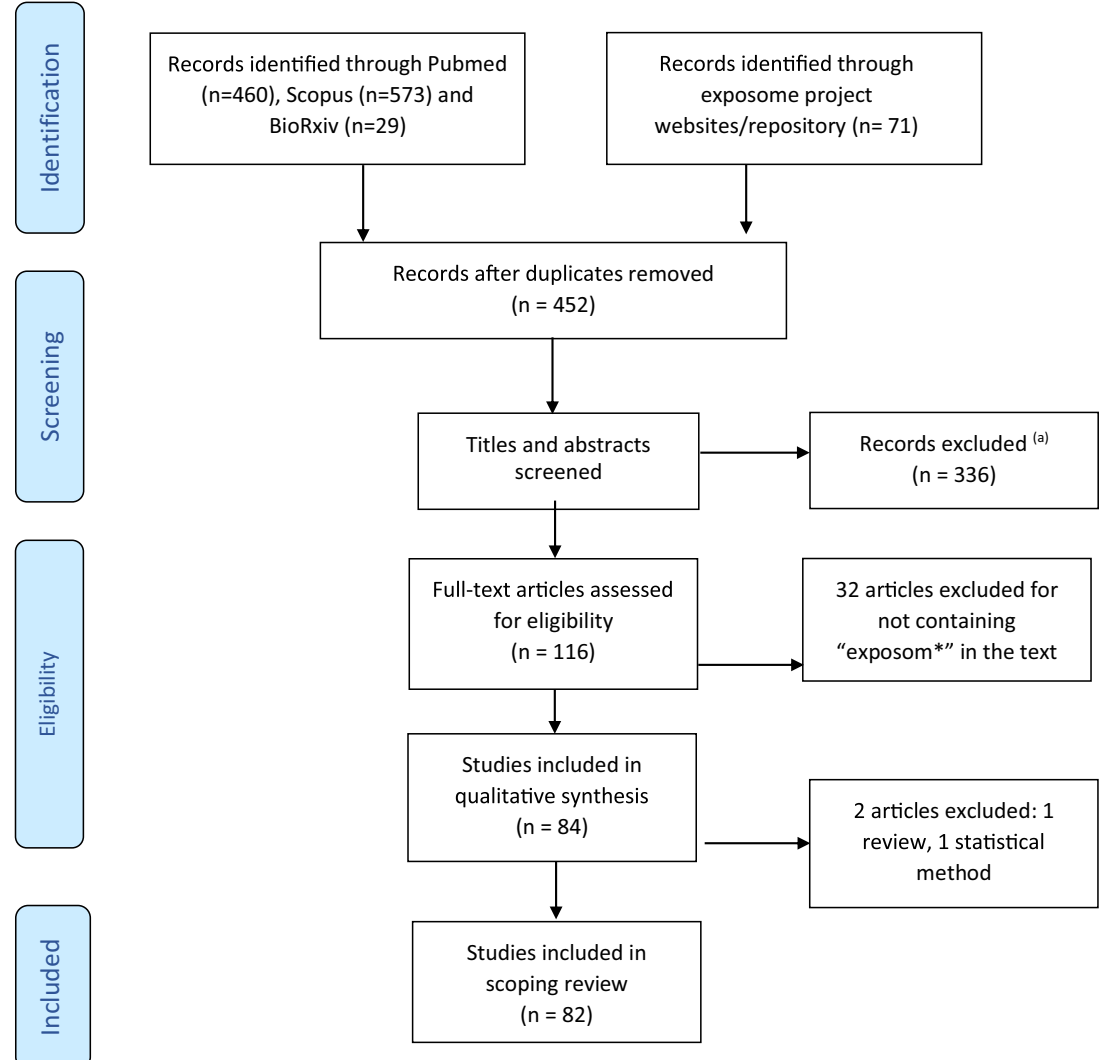

and the Turin center of the Piccolipiù study (Italy) [71]. Moreover, data from six large-scale Dutch cohort studies involving different age groups in the Netherlands were combined in a geo-coded database called the Geoscience and Health Cohort Consortium (GECCO) study [72].

Seventeen of the retained studies had a cross-sectional design (21\%) [73-89], and twelve were experimental (15\%) (i.e., three randomized trials on metabolomic profile alterations [90, 91] or clinical health outcomes [92] following administration of the experimental exposure; two open label cross-over trials exploring metabolomic and clinical effects of an experimental (juice) [93, 94] or environmental (airborne and grass pollen) intervention [95], and seven experimental non-randomized studies). Five studies were case-control (6\%) [94, 96-99] and three case-control studies nested in cohorts $(4 \%)$ [100-102]. In addition to studies that were based on primary data collection and analysis, some studies utilized secondary data, such as, county-aggregated level data (four studies (5\%)) [103-106], two studies used the National Health and Nutrition Examination Survey (NHANES) database (2\%) [107, 108] and another one used data collected from numerous occupational disease consultation centers in France (1\%) [109]. Also, one study was a retrospective case-series (1\%) using the dentine matrix [110]. Additionally, three studies (4\%) used data from the Human Metabolome Database (HMDB) $(n=2)[111,112]$ or the University of California Santa Cruz (USCS) Genome Browser [113]. Another study (1\%) conducted network medicine analysis of specific comorbidities [114]. Two studies [115, 116] (2\%) were similar in design, looking at pre-, and post-Katrina-induced changes in the environmental (soil) and blood signatures of lead for the affected communities. Finally, another study (1\%) conducted a secondary analysis of geochemical maps and cancer data at the municipality level [117]. Details of each retained study can be found in the Supplementary Information.

Country wise, about a third of the selected studies were conducted in the USA $(33 \%, n=28)$, whereas the majority of selected studies took place in Europe. Accounting for all epidemiological designs, 32 studies were conducted on population-based cohorts implemented in 14 countries (Fig. 2).

Between 2010 and 2018, there was an increasing (nonlinear) trend in the publication of exposome studies, using the criteria of this review (Fig. 3). In fact, 23 studies retained for this scoping review were published in 2018 alone, more than twice the number of retained exposome studies that were published in 2014 and more than twenty-fold of those published in 2010. Likewise, the mentions of the word "exposom*" per publication increased over the last years, 
suggesting an increasing awareness for this term in the global literature. For instance, a mean of 12 "exposom*" mentions were recorded in-text for the selected studies that were published in 2018, almost a six-fold and a two-fold increase in the mean of those published in 2012 and 2014, respectively.

\section{Participants' Profile, Interventions, and Outcomes Including Quality Assessment}

Studies focused solely on metabolomic and genomic human data from existing databases $(n=3)$ [111-113], plus a study applying the integrative network medicine analysis $(n=1)$ [114] were excluded for not fulfilling all components of the quality assessment tools, as these studies involved analysis of human data with no reference to selection criteria, blinding, confounding, or withdrawal rate.
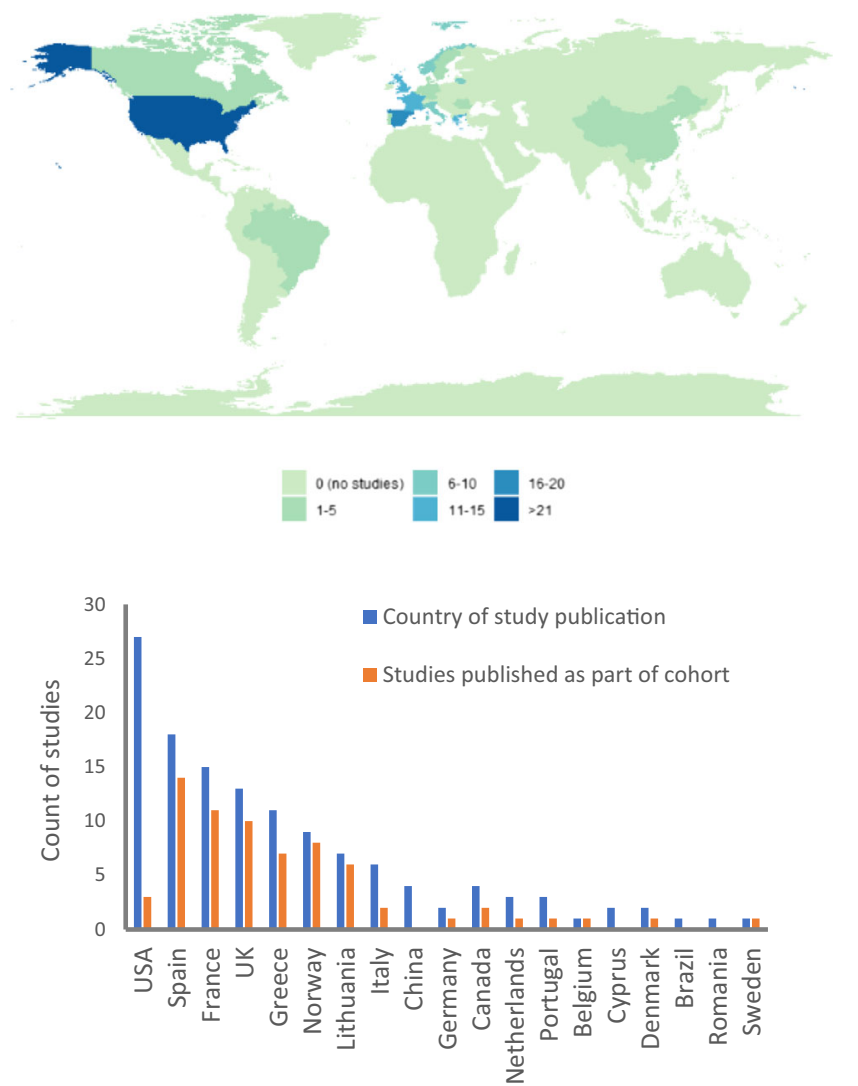

Fig. 2 Distribution of selected studies per country of publication and as part of cohorts. Studies being part of population-based cohorts: Human Early Life Exposome study (HELIX) (France, Greece, Lithuania, Norway, Spain, UK) $(n=8)$, INfancia y Medio Ambiente (INMASpain) $(n=4)$, Avon Longitudinal Study of Parents and Children (ALSPAC-United Kingdom) $(n=4)$, LIFE (USA) $(n=3)$, European Prospective Investigation Into Cancer and Nutrition EPIC (Denmark, France, Germany, Greece, Italy, Norway, Spain, Sweden, Netherlands, UK) $(n=1)$, MIREC (Canada) $(n=1)$, Rhea (Greece) $(n=1)$, LiNA (Germany) ( $n=1)$, PROBE (Italy) $(n=1)$, ENVIRONAGE (Belgium) $(n=1)$, Isis-Diab (France) $(n=1)$, GECCO (Netherlands), and KABC (UK). In addition, one study included cohorts of four different countries (ENVIRONAGE-Belgium, INMA-Spain, RHEA-Greece, TURIN-Italy)

\section{Profile of Participants}

In total, 78 studies were considered and $40(51 \%)$ of them were conducted on adults, of which two studies were conducted on couples. Twelve (16\%) studies were on pregnant women, $11(14 \%)$ on children (range of age $0.5-15.5$ years), and nine $(12 \%)$ focused on mother-child pairs. Additionally, three studies $(4 \%)$ were conducted on newborns and one $(1 \%)$ on adolescents. One study was conducted among pregnant women and non-related school children, whereas another one included data on adults ranging from 18 to 100 years from various Dutch cohorts.

\section{Interventions}

A total of seventeen studies (22\%) examined the association between environmental factors and clinical outcomes such as birth outcomes $(n=4)$, child development $(n=4)$, locus of control $(n=2)$, diabetes $(n=2)$, respiratory and allergy symptoms $(n=1)$, polycystic ovarian syndrome $(n=1)$ and multiple outcomes $(n=2)$, including biomarkers of effect such as semen quality $(n=1)[48,50,63,67,70,95,97,100,103$, 104, 106, 118-123]. Environmental factors were examined in association with gene expression profiling in four studies (5\%) $[65,71,78,108]$. Five studies $(6 \%)$ aimed to identify clusters of exposures, of which one was examined in association with obesity and another one with type II diabetes and all-cause mortality $[8,54,61,86,107]$.

In addition, twelve studies (16\%) aimed to characterize the endogenous response to a variety of environmental stimuli, such as endocrine disruptors (phthalate metabolites, phenols), non-persistent chemicals (dialkyl phosphate pesticides metabolites, and cotinine), and other environmental chemicals, such as organochlorine compounds (OCs), polybrominated diphenyl ethers (PBDEs), per- and poly-fluoroalkyl

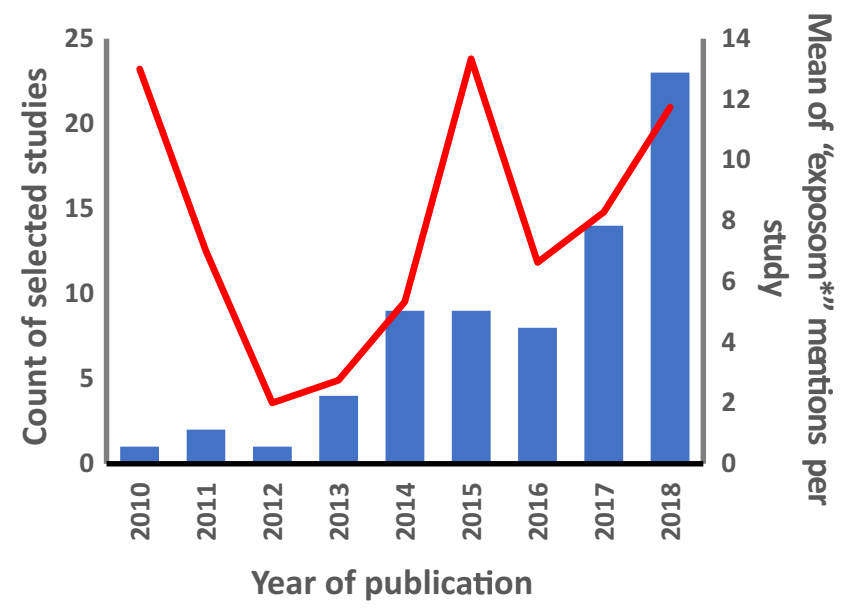

Fig. 3 Count of exposome studies and the of mean of "exposom*" mentions per study (red line) by year of publication. In 2019 and up to March 8,11 selected articles with a mean of 15 "exposom*" mentions per study were recorded 
substances (PFASs), and toxic and essential trace elements (e.g., cadmium) [64, 77, 46, 52, 57-59, 79, 81, 82, 84, 124]. On the other hand, three studies (4\%) explored the variability of the metabolomic profile through time: between sample collection time-points; pregnancy trimesters; or lifespan in women over 40 years old $[51,68,85]$.

Four studies $(5 \%)$ investigated the differentiation of metabolomics profiles by the following health end points/outcomes: oxidative stress, sarcoidosis, Crohn's disease, premature death, fetal growth, and blood pressure changes during pregnancy [56, 83, 96, 102].

On the other hand, a single study (1\%) analysed differential gene expression associated with hepatocellular carcinoma in Romania [87]. A "meet-in-the-middle" approach was applied to identify inflammatory pathways associated with cardio- and cerebrovascular disease and exposure to $\mathrm{NO}_{2}, \mathrm{NO}_{\mathrm{x}}$, and $\mathrm{PM}_{2.5}$ in a study $(1 \%)$ [101].

The endogenous response following administration of a specific exposure was assessed using metabolomics in 9 experimental studies (12\%) and in one cross-sectional study [88]. The experimental interventions were mainly exposure to air contaminants $(n=4)$, of which one was of occupational nature [91, 125-127]. Other studies examined the effects of juice intake $(n=2)[94,128]$, disinfection by-products $(n=2)$ $[93,125]$, and controlled food intake $(n=1)$ [60]. One randomized controlled trial considered the effects of vitamin D supplementation, fish oil intake and H1N1 vaccination [92]. There was also an -omics study (1\%) that conducted a gene expression analysis following an experimental exposure to diesel engine exhaust [129].

Nine exposome studies (12\%) focused on new methods of exposure measurements or applications; for instance, a study presented the application of the exposome paradigm in improving the efficiency of waste management strategies [69]; two studies highlighted novel exposure assessment techniques through personal monitoring devices for airborne biological and chemical exposures [47], and dental-matrix-based biomarkers of exposure to environmental contaminants [28]. Another study analyzed an environmental health exposure questionnaire using a novel statistical prediction method [75], whereas another evaluated a self-administered questionnaire on drug intake during pregnancy in comparison with drug urine screening using metabolomic methods [66]. Novel mass spectrometry techniques were presented for the detection of environmental contaminants in urine in two studies [49, 76], and for metabolite structural examination in one [99]. Statistical methods and modelling were presented in one study to define distinct endogenous phenotypes of childhood asthma [89].

Four studies $(5 \%)$ described the characteristics of exposome cohorts $[53,127,72,55]$ and another (1\%) characterized urban environmental and health indicators using the urban exposome framework [73]. Four studies (5\%) explored the partitioning of a contaminant between environmental and human biospecimen, of which three considered a biomarker of exposure to environmental contaminants as a study outcome $[117,115,80,116]$, while only one study (1\%) linked occupational records to health outcomes [109].

Novel agnostic tools of the exposome characterization were extensively used in 16 studies (20\%), where 9 exposome studies (11\%) employed the EWAS approach [50, 63, 73, 61, $67,69,79,86,107] ; 3(4 \%)$ studies used the GWAS approach $[71,78,92]$ and $2(3 \%)$ used the so-called MWAS approach $[84,88]$; another publication $(1 \%)$ [59] reported the use of an exposome-metabolome wide association study, and another one (1\%) [108] employed both an EWAS and a GWAS approach.

\section{Outcome}

Most exposome studies clearly defined a health outcome in their methodology (48 studies, 61\%). Twenty studies (42\%) tackled non-communicable diseases, mainly respiratory and allergy symptoms, diabetes, cancer, cerebro- and cardiovascular diseases, sarcoidosis, Crohn's disease, polycystic ovarian syndrome, and health status as well as the presence of any chronic disease.

Five studies explored other end points of a disease or biomarkers of effect, such as locus of control $(n=2,4 \%)$, oxidative stress $(n=1,2 \%)$ and semen quality $(n=1,2 \%)$, or incident occupational diseases $(n=1,2 \%)$. Birth outcomes and child developmental markers were studied in seven $(15 \%)$ and six (12\%) articles, respectively. The biological response after an external exposure was measured in five studies (10\%) using metabolomics in four of them and inflammatory response in the fifth study. As for transcriptomics, DNA methylation was explored in two studies (4\%), gene expression and inflammatory pathways in two (4\%), while telomere length and genotype variation were explored separately in one study, each (2\%). On the other hand, a total of 28 studies (36\%) did not consider a health outcome, where about half of them (12 in number) compared data from biomarker of exposure measurements.

\section{Exposome Domains Explored}

The holistic inclusion of all three domains (general external, specific external, and internal) and the use of only the specific external and the internal exposome domains was practiced by $37(48 \%)$ and $33(42 \%)$ studies, respectively; eight articles $(10 \%)$ focused solely on the internal domain. For every exposome domain explored, a few groups emerged based on the type of specific variables (components) sharing common characteristics that allowed for their grouping in a qualitative form of a cluster (Table 1). It is noteworthy mentioning that a study could employ more than one out of the three exposome 


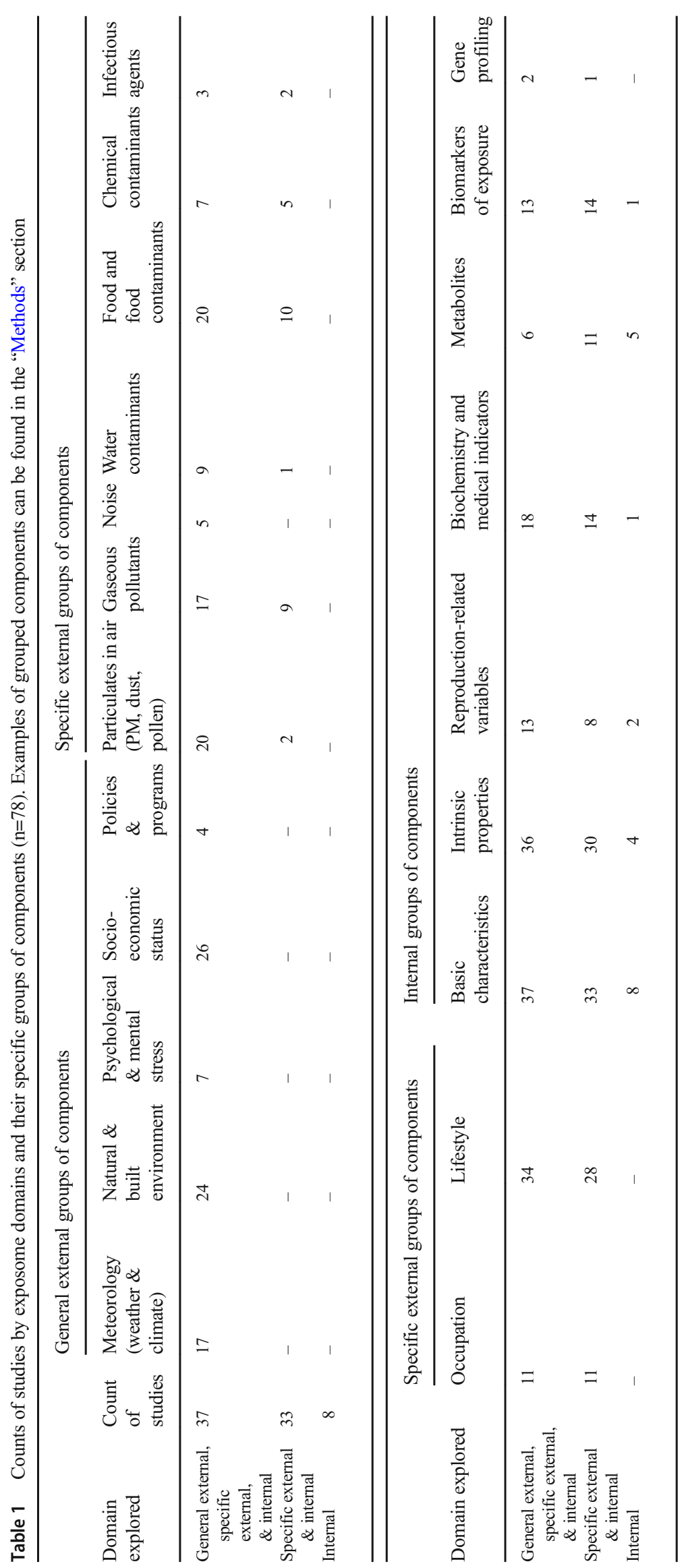


domains, and/or using a single/multiple exposure(s) and/or outcome(s) assessment methods.

The following groups of components were generated after the comprehensive analysis of the exposome domains from all selected studies: (i) five groups for the general external domain-meteorology and climate, natural and built environment, psychological and mental stress, socioeconomic status, and health policies/programs; ten groups for the specific external domain-particulates in air, gaseous pollutants, noise, soil contaminants, water contaminants, food and food contaminants, chemical contaminants, infectious agents, occupation, and lifestyle; and seven groups for the internal domain-intrinsic properties, basic characteristics, reproduction-related, biochemistry and medical indicators, metabolites (from metabolomics platforms), biomarkers of exposure, gene expression, and background characteristics. The occurrence of the specific groups varied from study to study and by domain with few groups being more frequently encountered (basic characteristics, intrinsic properties, lifestyle, socioeconomic status, and natural and built environment), frequently encountered (particulates in air, food and food contaminants, gaseous pollutants, biochemistry/medical indicators, and climate/meteorology) and less frequently encountered (metabolites, psychological and mental stress, health policies/programs, noise, soil, water, infectious agents, and gene expression) (Table 1).

Regarding the exposure and outcome assessment, one or more tools/methods were employed by each study. For exposure assessment (Table 2), self-reported exposures and biomarkers of exposures were used in $37(47 \%)$ and 28 studies (36\%), respectively. Twenty-two studies $(28 \%)$ relied on the use of metabolomics while three (4\%) used genomics. Nineteen studies (24\%) used secondary data from existing datasets, such as from governmental data and hospital records. Personal devices/sensors were deployed in 12 studies (15\%) ranging from active and passive air samplers to capture biological and chemical particulates to personal trackers for physical activity and meteorological data; whereas $10(13 \%)$ used satellite imaging and geospatial modelling. Seven studies $(9 \%)$ conducted specific environmental testing. In addition, seven studies $(9 \%)$ relied on a clinical assessment to identify the nature of the mineral and metal particles in lung tissue as well as biochemical indicators in serum and amniocentesis.

In studies with a clearly defined health outcome $(n=48)$, clinical assessment was the main source of outcome assessment $(n=29,60 \%)$, followed by self-reported outcomes $(n=$ $12,25 \%)$ and the use of secondary data sources from existing datasets $(n=10,21 \%)$. Nine studies $(19 \%)$ relied on metabolomics, while twelve (25\%) used genomics and gene profiling to assess the outcome (Table 3 ).

\section{Overall Quality of the Selected Studies}

Most of the rated studies $(n=47,60 \%)$ were evaluated as of having weak quality, and $28(36 \%)$ as moderate. However, only three studies had strong quality assessment according to the EPHPP tool evaluation dictionary [45] (refer to Supplementary Information). Selection bias was the main reason behind the classification of studies as weak $(n=41,87 \%)$ or moderate $(n=16$, $57 \%)$ in quality. The second most frequently encountered quality component was the study design with 20 $(42 \%)$ and $8(29 \%)$ receiving "weak" rating in studies classified as "overall weak" and "overall moderate", respectively. Confounding was rated as "weak" in 26 "overall weak studies" (54\%), but only in 3 was classified as "overall moderate" (10\%). The blinding component was rated as "weak" in 7 "overall weak" (15\%). Also, none of the "overall moderate studies" had a "weak" rating for the data collection component. As for the withdrawal component, it was rated "weak" for 13 "overall weak" studies (27\%) and 2 "overall moderate" studies (7\%) (Figs. 4 and 5).

There were no apparent differences in the overall quality of the studies with respect to the explored exposome domains In addition, the examination of the overall quality rating with the study sample size did not show any differences, since both "overall weak" and "overall moderate" studies included sample sizes as low as 5 and 6 individuals, respectively, up to 56,334 and 225,375 participants, respectively.

\section{Discussion}

Almost 15 years have passed since the inaugural definition of the human exposome as a breakthrough concept to describe the role of environmental exposures in disease onset and development. It is about time to step back and reflect on the use and, possibly, misuse of the term exposome by analyzing the characteristics of the published exposome studies. This scoping review highlighted the partial assessment of the totality of environmental exposures and the non-standardized or nonharmonized use of the term exposome that seems to be challenged by nuanced perspectives and understandings. What is also emerging is that the practical application of the exposome paradigm is somewhat hampered by failing to acknowledge the comprehensive and holistic nature of the human exposome.

A few observations were noted by this scoping review. First, it is noteworthy that the number of exposome-related reviews, perspectives, and commentaries $(n=215)$ was exceptionally high compared with the number of publications presenting original exposome research, highlighting the ongoing 
Table 2 Count (\%) of exposure assessment approaches in exposome studies $\mathrm{n}=78$

\begin{tabular}{|c|c|c|}
\hline Approach & Specific tools & Count $(\%)$ \\
\hline Self-reported & Structured questionnaires and face-to-face interviews & $37(47 \%)$ \\
\hline Biomarkers & $\begin{array}{l}\text { Blood lead or mercury levels; VOC analysis } \\
\text { in exhaled breath; Analysis of bronchoalveolar } \\
\text { lavage fluid by transmission electron microscopy }\end{array}$ & $28(36 \%)$ \\
\hline \multirow[t]{2}{*}{ Omics platforms } & Metabolomics & $22(28 \%)$ \\
\hline & Genomics/gene profiling & $3(4 \%)$ \\
\hline Existing datasets & $\begin{array}{l}\text { County data; governmental portal data; governmental weather service; } \\
\text { hospital records }\end{array}$ & $19(24 \%)$ \\
\hline Personal/portable sensor devices & $\begin{array}{l}\text { Air (passive and active) samplers to capture biological and chemical } \\
\text { particulates (Potentially Toxic Elements (PTE); VOC; DBP; jet fuel); } \\
\text { IOM inhalable dust sampler; volumetric trap for grassborne and airborne } \\
\text { pollen; accelerometer to measure physical activity; light scattering sensor } \\
\text { for particulate matters, temperature, humidity; unipolar diffusion charger } \\
\text { for ultrafine particles measures; optical absorption method for black carbon; } \\
\text { smartphone GPS; actigraph accelerometer; electronic wristband UV dosimeters; }\end{array}$ & $12(15 \%)$ \\
\hline Geospatial modelling and remote sensing & $\begin{array}{l}\text { Land-use regression data and prediction models; Thermal imagery; Spatial } \\
\text { temporal interpolation method }\end{array}$ & $10(13 \%)$ \\
\hline Environmental testing & $\begin{array}{l}\text { Water testing for microbiological and chemical contaminants (DBP); } \\
\text { Analysis of olive tree leaves for OC; Dust samples from bedding; Flame } \\
\text { atomic absorption spectrometer for airborne manganese analysis }\end{array}$ & $7(9 \%)$ \\
\hline Clinical assessment & $\begin{array}{l}\mathrm{X} \text {-ray emission spectroscopy and optical microscopy for mineral/metal lung } \\
\text { content, amniocentesis, biochemistry serum testing }\end{array}$ & $7(9 \%)$ \\
\hline
\end{tabular}

theoretical interest and debate about the exposome's utility and applications. Secondly, this global mapping exercise revealed that all exposome studies were published in 19 countries exclusively, mostly in European countries, perhaps due to greater availability of exposome-related funding opportunities, where several exposome projects exist, such as HELIX [130], EXPOsOMICS [131], and HEALS [42]. Thirdly, although the use of the word "exposom*" in the main text, abstracts or keywords is on the rise, there seems to be a lack of a commonly accepted exposome language. For instance, Catinon et al. [96] quantified the "mineral exposome," or what they referred to as occupational and non-occupational dust exposure. The "seasonality" of the exposome studied by Paglia et al. [60] evaluated the year-round variability of toxic and essential elements in urine specimen. On the other hand,
Schisler et al. [129] highlighted the importance of considering the "plasma exposome" as it comprises the functionality of all endothelial cells in the body, thus providing a comprehensive capture of the systemic inflammatory network. The "urban exposome" framework that was recently developed extends the utility of the human exposome into that of a city, considering the city elements as the main units of measuring a city's exposome, complementing that of the human exposome [73]. The above serve as examples of efforts towards further refining the exposome concept and its utility [9]. Moreover, this scoping review showcased either the partial incorporation of the exposome domains into the study protocols of various exposome projects, or the introduction of newly defined exposome domains distantly proposed from the original Wild's definition. For example, when assessing the perception
Table 3 Count (\%) of outcome assessment approaches in exposome studies $(n=48)$

\begin{tabular}{llr}
\hline Approach & Tools & Count (\%) \\
\hline Clinical assessment & $\begin{array}{l}\text { Clinical characteristics (assessment and diagnosis of clinical } \\
\text { conditions including birth characteristics, cardiovascular fitness } \\
\text { and lung function, assessment of child communication, } \\
\text { movement assessment and neurological development, blood }\end{array}$ & $29(60 \%)$ \\
& $\begin{array}{l}\text { immune or inflammatory biomarkers, fertility monitoring); } \\
\text { locus of control; broncholalveolar lavage for diagnosis of sarcoidosis }\end{array}$ & \\
Self-reported & $\begin{array}{l}\text { Structured questionnaires and face-to-face interviews } \\
\text { Existing datasets }\end{array}$ & $\begin{array}{l}\text { Hospital records; obstetric records; occupational records; } \\
\text { governmental health data; epidemiological studies }\end{array}$ \\
Omics platform & $\begin{array}{l}\text { Metabolomics } \\
\text { Genomics/gene profiling }\end{array}$ & $10(21 \%)$ \\
& & $9(19 \%)$ \\
\hline
\end{tabular}




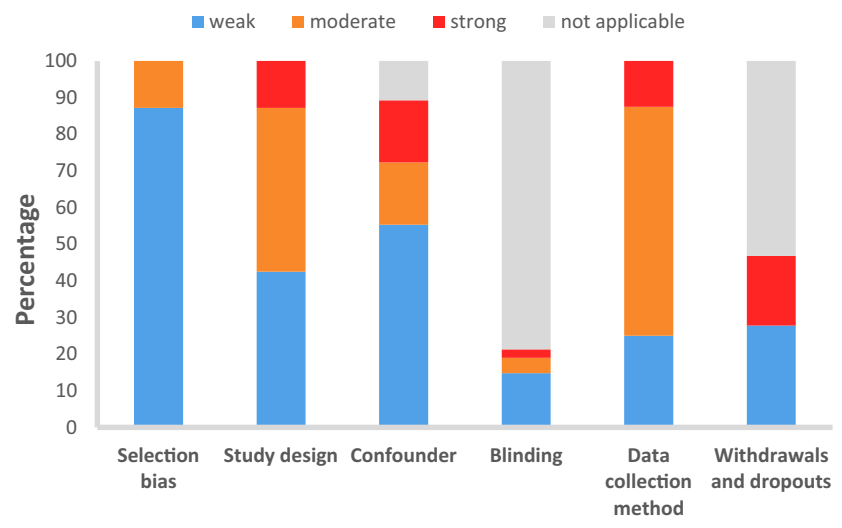

Fig. 4 Description of studies classified as "weak" by rating component $(n=47)$

of environmental contaminants within the context of the built environment, Chen et al. [75] defined five exposome domains (home and hobby, school, community, occupation, and exposure history). The partial incorporation of the exposome domains was reflected onto studies that concomitantly examined the specific external or general external and internal domains, instead of all three domains as originally proposed by Dr. Wild. Is this a natural progression of the exposome definition or a partially covered definition in practice? In addition, the issue is perplexed by the fact that several components of each domain addressed in the selected studies could be grouped into distinct exposome component groups, such as particulates in air, infectious agents, and water contaminants (details in "Results" section). It quickly became evident that these specific groups of components were not equally tackled among selected studies. For instance, in the specific external domain, emphasis was paid more frequently on the group of lifestyle exposures, or the group of exposures to particulates in air, and to a lesser extent to water contaminants, or infectious agents. A standardized mode of inclusion for all domains and as many as possible of their component groups may be warranted for the

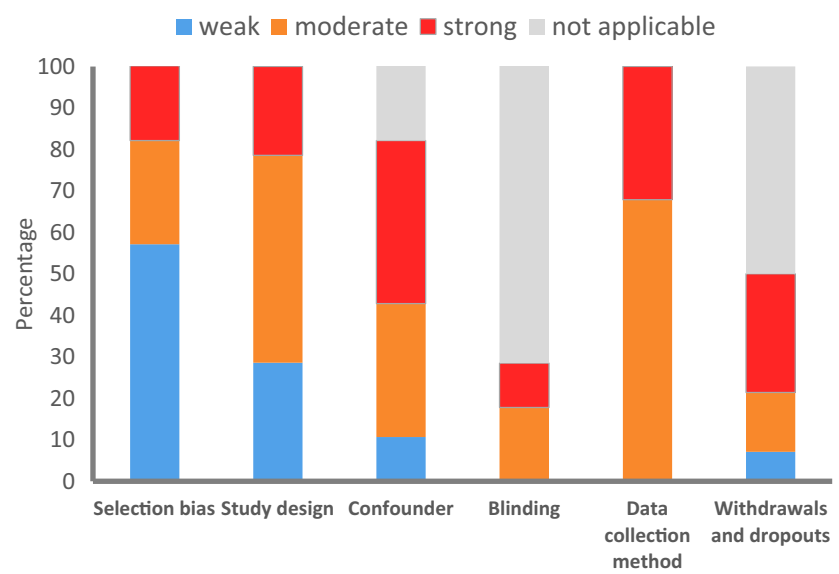

Fig. 5 Description of exposome studies classified as "moderate" by rating component $(n=31)$ design of future exposome studies, if we were to further refine and expand its utility and applications.

It was quite clear that most of the selected studies followed a longitudinal design, abiding by the dynamic nature of the exposome and the need to prospectively follow the evolution of the exposome along with that of the disease process in populations at critical life time windows. Most of these were cohort-based exposome studies targeting middle-aged adults; one could argue that this trend would be eloquently deviating from the theoretical guidelines of the exposome concept that call for focusing on specific windows of susceptibility [2]. Hence, the importance of assessing "life-course exposure" and the consideration of critical windows of susceptibility (i.e., during pregnancy, and child development) needs to be again emphasized during the re-alignment process of the exposome's methodological framework.

Further, the exposome tools and methodologies have been embraced by the exposome community to a varying extent. The classical collection mode of self-reported data, existing government/official routine datasets, and clinical measurements remain the most commonly used instruments for both exposure and outcome assessment in exposome studies. The use of targeted/untargeted biomarkers of exposure/effect coupled with the introduction of -omics platforms and personal wearables represent the core of emerging technologies and platforms that accompany the application of the human exposome in practice. This "multi-faceted approach" for measuring the exposome was earlier acknowledged by Dr. Wild [2] underscoring the need of coupling refined conventional tools along with innovative technologies for the assessment of the exposome domains. Dennis et al. discussed the challenges and benefits of applying either the classical (questionnaire data and ecological, environmental, or biological measurements) and non-classical biomonitoring methods (untargeted analyses), emphasizing the need to combine both in order to capture complex endogenous and exogenous exposures throughout life-course [31]. The use of personal sensors may not yet be that widespread in exposome studies $(n=$ 12 ), but seems to be gradually growing in use for the measurement of meteorological, air quality, and activity tracking parameters. With the development of more advanced technologies such as mobile applications and smart, wearable sensors, a promising, yet challenging, collection of long-term exposures with geospatial coverage may become the norm in the near future [130]. Mining data from metabolomics (such as HMDB) or genomics ((USCS) genome browser) databases may be also proven to be an innovative tool for the characterization of the human exposome. Dennis et al. [31] acknowledged the notable efforts to develop, expand and further improve the quality and coverage of these databases in order to facilitate multi-group data inclusion from multiple databases.

Despite being promoted as a novel concept in the field of both environmental health and biomedical sciences, the exposome 
concept has yet to find its way into health care settings and in personalized and precision medicine, which is currently dominated by pharmacogenomics applications. Our scoping review showed that health care facilities (e.g., hospitals/clinics) have been so far used only as part of a sampling framework $(n=9$ studies), and not as a setting for implementing the exposome in precision medicine applications. Obviously, this is a novel niche for the future of the exposome utility.

An exploratory feature of our scoping review was the quality assessment of the exposome studies. Judged against the six rating components of EPHPP, most of the exposome studies were rated as "overall weak," because of selection bias. This issue of population representativeness and convenience sampling was earlier raised as a result of the choice of sampling framework as well as participation and completion rate, and it was manifested as a main concern when interpreting findings from observational exposome studies [9]. Confounding was another quality indicator for which rating was "overall weak" for most exposome studies. As previously discussed [6], the identification of confounders may be problematic in an exposome study design in the sense that the totality of exposures is inter-dependently considered.

The main strength of this analysis is that this is the first global scoping review that conducted an exhaustive mapping of relevant exposome studies to date. The main limitation of the work refers to restricting the selection of articles to those using the word "exposom*" in the main text, abstract, or keywords. This could have possibly resulted in excluding studies and projects that their methodology obviously abided by the exposome definition, but somehow the terminology was not clearly conveyed in their publications, such as those by the Japan Environment and Children's Study (JECS), one of the most comprehensive and largest exposome projects, worldwide $[1,3,6]$. Another limitation lies in the difficulty in clearly classifying certain environmental exposure variables into a distinct domain due to their domain-overlapping properties. For instance, one could argue that socio-economic status could be part of the general external domain as originally proposed by Wild [2] or alternatively could be grouped within the specific external domain, since it is closely related to lifestyle and behavioral aspects. Another problematic categorization could be that of psychological and mental stress, where one could also argue that it belongs into the general external domain and not in the specific external domain.

The overlapping area between two exposome domains could lead to concerns over the biological plausibility of each domain to the chosen disease outcome(s). A relevant question arises: Shall all three domains and their groups of components as identified here be included in the design of an exposome study in order to fully characterize the exposome, including its biological relevance towards disease development? One could argue that the specific groups of components in each domain carry a biological fingerprint related to the health outcome that should be accounted for during design and methodological aspects of a future exposome study. Bringing these details forward, it could help identifying specific groups of components that may be either under-studied or left out during the methodological queries of a new study. For example, mental health, regardless of the domain to which it is assigned, continues to be understudied in exposome research despite its crucial role in the fields of public health, health care, and treatment. On the other hand, emerging exposures of our times, e.g., non-ionizing radiation and electronic screen time, have not yet been the focus of an exposome study. Hence, it is recommended that future exposome research invests time and resources towards further widening the scope and breadth of exposome domains tackled, rather than including fragmented exposome domains. It is imperative that an exposome focused cohort should be established considering critical lifetime windows of susceptibility that better inform the disease process.

\section{Conclusion}

Given its overarching nature, characterizing the exposome relies on the complete measurement of dynamic exposures occurring through lifespan, using both conventional and innovative exposure assessment methods and tools. This exciting research paradigm requires the use of an inter-disciplinary approach, allowing for the inclusion of all domains and their specific groups of components that are relevant to the health outcome(s) of interest. Exposome-related literature has recently expanded, yet with remaining conceptual ambiguities. Widening the scope and breadth of the three exposome domains (general external, specific external, internal) as well as standardization of the exposure(s)/outcome(s) assessment methods are critical in order to move forward with the human exposome research and its utility. Finally, a standardized quality assessment tool that would evaluate the exposome domains and specific groups of components explored, used tools, and applied statistical methods is warranted.

Funding Information This work was made possible thanks to the EXPOSOGAS project awarded to K.C. Makris that received funding from the European Union's Horizon 2020 research and innovation program under grant agreement No 810995.

\section{Compliance with Ethical Standards}

Conflict of Interest On behalf of all authors, the corresponding author states that there is no conflict of interest.

Open Access This article is distributed under the terms of the Creative Commons Attribution 4.0 International License (http:// creativecommons.org/licenses/by/4.0/), which permits unrestricted use, distribution, and reproduction in any medium, provided you give appropriate credit to the original author(s) and the source, provide a link to the Creative Commons license, and indicate if changes were made. 


\section{References}

1. Wild CP. Complementing the genome with an "exposome": the outstanding challenge of environmental exposure measurement in molecular epidemiology. Cancer Epidemiol Biomark Prev. 2005. https://doi.org/10.1158/1055-9965.EPI-05-0456.

2. Wild CP. The exposome: from concept to utility. Int J Epidemiol. 2012. https://doi.org/10.1093/ije/dyr236.

3. Juarez PD, Matthews-Juarez P, Hood DB, Im W, Levine RS, Kilbourne BJ, et al. The public health exposome: a populationbased, exposure science approach to health disparities research. Int J Environ Res Public Health. 2014. https://doi.org/10.3390/ ijerph111212866.

4. Loh M, Sarigiannis DA, Gotti A, Karakitsios S, Pronk A. How sensors might help define the external exposome. Int J Environ Res Public Health. 2017;14(4) Retrieved from https://doi.org/10. 3390/ijerph14040434.

5. Vrijheid M. EThe exposome: a new paradigm to study the impact of environment on health. Thorax. 2014. https://doi.org/10.1136/ thoraxjnl-2013-204949.

6. Stingone JA, Buck Louis GM, Nakayama SF, Vermeulen RCH, Kwok RK, Cui Y, et al. Toward greater implementation of the exposome research paradigm within environmental epidemiology. Annu Rev Public Health. 2017;38(1):315-27. https://doi.org/10. 1146/annurev-publhealth-082516-012750.

7. Gangler S, Waldenberger M, Artati A, Adamski J, van Bolhuis JN, Pettersen Sørgjerd E, et al. Exposure to disinfection byproducts and risk of type 2 diabetes: a nested case-control study in the HUNT and lifelines cohorts. Metabolomics. 2019;15(60).

8. Kiossoglou P, Borda A, Gray K, Martin-Sanchez F, Verspoor K, Lopez-Campos G. Characterising the scope of exposome research: a generalisable approach. Stud Health Technol Informat. 2017;245:457-61. https://doi.org/10.3233/978-1-61499-830-3457.

9. Buck Louis GM, Smarr M, Patel CJ. The exposome research paradigm: an opportunity to understand the environmental basis for human health and disease. Curr Environ Health Rep. 2017;4(1):89-98.

10. Buck Louis GM, Sundaram R. Exposome: time for transformative research. Stat Med. 2012. https://doi.org/10.1002/sim.5496.

11. Holland N. Future of environmental research in the age of epigenomics and exposomics. Rev Environ Health. 2017;32(12):45-54.

12. Miller GW, Jones DP. The nature of nurture: refining the definition of the exposome. Toxicol Sci. 2014;137(1):1-2.

13. Olympio KPK, Salles FJ, Ferrreira APS d S, Pereira EC, de Oliveira AS, Leroux IN, et al. The human exposome unraveling the impact of environment on health: promise or reality? Rev Saude Publica. 2019;53(6):6.

14. Renz H, Holt P, Inouye M, Prescott S, Sly P. An exposome perspective: early-life events and immune development in a changing world. J Allergy Clin Immunol. 2017;140(1):24-40.

15. Smith M, de la Rosa R, Daniels SI. Using exposomics to assess cumulative risks and promote health. Environ Mol Mutagen. 2015;56(9):715-23.

16. Juarez PD, Matthews-Juarez P. Applying an Exposome-wide (ExWAS) approach to cancer research. Front Oncol. 2018;8(Aug). https://doi.org/10.3389/fonc.2018.00313.

17. Schetter A, Harris C. Tumor suppressor p53 (TP53) at the crossroads of the exposome and the cancer genome. Proc Natl Acad Sci U S A. 2012;109(21):7955-6. https://doi.org/10.1073/pnas. 1205457109.

18. Derumeaux GA. From metabolic exposome to onset of diabetic cardiomyopathy. JACC Cardiovasc Imaging. 2017;10(2). https:// doi.org/10.1016/j.jcmg.2016.03.015.
19. Ananthakrishnan A. The exposome in inflammatory bowel disease. Trop Gastroenterol. 2014;35(3).

20. Mapesa JO, Maxwell AL, Ryan EP. An exposome perspective on environmental enteric dysfunction. Environ Health Perspect. 2016;124(8) https://doi.org/10.1289/ehp.1510459.

21. Goldfarb DS. The exposome for kidney stones. Urolithiasis. 2016;44(1):3-7.

22. Krutmann J, Bouloc A, Sore G, Bernard B. The skin aging exposome. J Dermatol Sci. 2017;85(3):152-61.

23. Miller DB, O'Callaghan JP. Biomarkers of Parkinson's disease: present and future. Metab Clin Exp. 2015;64(3 Suppl 1):S40-6. https://doi.org/10.1016/j.metabol.2014.10.030.

24. Buhimschi IA, Buhimschi CS. Proteomics/diagnosis of chorioamnionitis and of relationships with the fetal exposome. Semin Fetal Neonatal Med. 2012;17(1):36-45.

25. Lewis MR, Demmelmair H, Gaillard R, Godfrey K, Hauguel-de Mouzon S, Huppertz B, et al. The placental exposome: placental determinants of fetal adiposity and postnatal body composition. Ann Nutr Metab. 2013;63:208-15.

26. Robinson O. The pregnancy exposome. Curr Environ Health Rep. 2015;2(2):204-13.

27. Wright ML. Mechanisms of the maternal exposome and implications for health outcomes. ANS Adv Nurs Sci. 2016;39(2).

28. Andra SS, Austin C, Arora M. The tooth exposome in children's health research. Curr Opin Pediatr. 2016a;28(2):221-7.

29. Betts KS. Characterizing exposomes: tools for measuring personal environmental exposures. Environ Health Perspect. 2012;120(4): a158-63.

30. Debord DG, Carreón T, Lentz TJ, Middendorf PJ, Hoover MD, Schulte PA. Primer on -omic technologies. American Journal of Epidemiology 2017;184(4):302-14. https://doi.org/10.1093/aje/ kwv325.

31. Dennis KK, Marder E, Balshaw DM, Cui Y, Lynes MA, Patti GJ, et al. Biomonitoring in the era of the exposome. Environ Health Perspect. 2017;125(4):502-10.

32. Loh M, Sarigiannis DA, Gotti A, Karakitsios S, Pronk A. How sensors might help define the external exposome. Int J Environ Res Public Health. 2017;14(4) Retrieved from https://doi.org/10. 3390/ijerph14040434.

33. Putignani L, Dallapiccola B. Foodomics as part of the host-microbiota-exposome interplay. J Proteome. 2016;147:3-20.

34. Higgins JP, Green S. In: Higgins JP, Green S, editors. Cochrane handbook for systematic reviews of interventions. 2018th ed: Wiley-Blackwell; 2018.

35. Aromataris E, Munn Z (2017) The Joanna Briggs Institute reviewers manual. Retrieved from The Joanna Briggs Institute Reviewers Manual website: https://reviewersmanual. joannabriggs.org/ Acccessed February 14th, 2019

36. Pubmed US National Library of Medicine National Institutes of Health. (n.d.). Retrieved August 18, 2019, from https://www.ncbi. nlm.nih.gov/pubmed/

37. Scopus Preview. Retrieved August 18, 2019, from https://www. scopus.com/

38. bioRvix.org. The Preprint Server for Biology. (n.d.). Retrieved August 18, 2019, from https://www.biorxiv.org/

39. The Human Exposome Project. (2019). Retrieved August 6, 2019, from https://humanexposomeproject.com

40. HELIX. (2019). Retrieved August 6, 2019, from http:// projecthelix.eu/

41. Exposome-CIRCLE. (2019). Retrieved September 20, 2003, from exposome-CIRCLE website: http://circle.berkeley.edu/research/ exposome/ Accessed July 26, 2019

42. HEALS. (2019). Retrieved September 20, 2003, from HEALS website: http://www.heals-eu.eu 
43. CORDIS. (2019). Retrieved September 20, 2003, from CORDIS website: https://cordis.europa.eu/project/rcn/105526/results/en

44. Zeng X, Zhang Y, Kong JSW, Zhang C, Li S, Sun F, et al. The methodological quality assessment tools for preclinical and clinical studies, systematic review and meta-analysis, and clinical practice guideline: a systematic review. J Evidence-Based Med. 2015;8(1). https://doi.org/10.1111/jebm.12141

45. Effective Public Health Practice Project. (2010). Retrieved from https://merst.ca/ephpp/ Accessed February 14, 2019

46. Jamin EL, Bonvallot N, Tremblay-Franco M, Cravedi JP, Chevrier $\mathrm{C}$, Cordier S, et al. Untargeted profiling of pesticide metabolites by LC-HRMS: an exposomics tool for human exposure evaluation. Anal Bioanal Chem. 2014;406(4):1149-61. https://doi.org/10. 1007/s00216-013-7136-2.

47. Jiang C, Wang X, Li X, Inlora J, Wang T, Liu Q, et al. Dynamic human environmental exposome revealed by longitudinal personal monitoring. Cell. 2018;175(1):277-291.e31. https://doi.org/10. 1016/j.cell.2018.08.060.

48. Nayeri UA, Buhimschi CS, Zhao G, Buhimschi IA, Bhandari V. Components of the antepartum, intrapartum, and postpartum exposome impact on distinct short-term adverse neonatal outcomes of premature infants: a prospective cohort study. PLoS ONE. 2018;13(12):1-18. https://doi.org/10.1371/journal.pone. 0207298.

49. Yao Y, Wang P, Shao G, Del Toro LVA, Codero J, Giese RW. Nontargeted analysis of the urine nonpolar sulfateome: a pathway to the nonpolar xenobiotic exposome. Rapid Commun Mass Spectrom. 2016;30(21):2341-50. https://doi.org/10.1002/rcm. 7726.

50. Agier L, Basagaña X, Maitre L, Granum B, Bird PK, Casas M, et al. Early-life exposome and lung function in children in Europe: an analysis of data from the longitudinal, population-based HELIX cohort. Lancet Planet Health. 2019;3(2):e81-92. https://doi.org/ 10.1016/S2542-5196(19)30010-5.

51. Casas M, Basagaña X, Sakhi AK, Haug LS, Philippat C, Granum $\mathrm{B}$, et al. Variability of urinary concentrations of non-persistent chemicals in pregnant women and school-aged children. Environ Int. 2018;121(Pt 1):561-73. https://doi.org/10.1016/j.envint.2018. 09.046 .

52. Haug LS, Sakhi AK, Cequier E, Casas M, Maitre L, Basagana X, et al. In-utero and childhood chemical exposome in six European mother-child cohorts. Environ Int. 2018;121(September):751-63. https://doi.org/10.1016/j.envint.2018.09.056.

53. Maitre L, de Bont J, Casas M, Robinson O, Aasvang GM, Agier L, et al. Human early life Exposome (HELIX) study: a European population-based exposome cohort. BMJ Open. 2018b. https:// doi.org/10.1136/bmjopen-2017-021311.

54. Tamayo-Uria I, Maitre L, Thomsen C, Nieuwenhuijsen MJ, Chatzi L, Siroux V, et al. The early-life exposome: description and patterns in six European countries. Environ Int. 2019;123(December 2018):189-200. https://doi.org/10.1016/j. envint.2018.11.067.

55. Valentin A, Maitre L, McEachan R, Lepeule J, Ambros A, Nieuwenhuijsen $\mathrm{M}$, et al. The urban exposome during pregnancy and its socioeconomic determinants. Environ Health Perspect. 2018;126(7):077005. https://doi.org/10.1289/ ehp2862.

56. Warembourg C, Basagaña X, Seminati C, de Bont J, Granum B, Lyon-Caen S, et al. Exposure to phthalate metabolites, phenols and organophosphate pesticide metabolites and blood pressure during pregnancy. Int J Hyg Environ Health. 2019;222(3):44654. https://doi.org/10.1016/j.ijheh.2018.12.011.

57. Maitre L, Villanueva CM, Lewis MR, Ibarluzea J, Santa-Marina $\mathrm{L}$, Vrijheid M, et al. Maternal urinary metabolic signatures of fetal growth and associated clinical and environmental factors in the
INMA study. BMC Med. 2016;14(1):1-12. https://doi.org/10. 1186/s12916-016-0706-3.

58. Maitre L, Lau CHE, Vizcaino E, Robinson O, Casas M, Siskos AP, et al. Assessment of metabolic phenotypic variability in children's urine using 1H NMR spectroscopy. Sci Rep. 2017;7(April): 1-12. https://doi.org/10.1038/srep46082.

59. Maitre L, Robinson O, Martinez D, Toledano MB, Ibarluzea J, Marina LS, et al. Urine metabolic signatures of multiple environmental pollutants in pregnant women: an exposome approach. Environ Sci Technol. 2018a;52(22):13469-80. https://doi.org/10. 1021/acs.est.8b02215.

60. Paglia G, Miedico O, Tarallo M, Lovino AR, Astarita G, Chiaravalle AE, et al. Evaluation of seasonal variability of toxic and essential elements in urine analyzed by inductively coupled plasma mass spectrometry. Expos Health. 2017;9(2):79-88. https://doi.org/10.1007/s12403-016-0222-x.

61. Robinson O, Basagaña X, Agier L, De Castro M, HernandezFerrer C, Gonzalez JR, et al. The pregnancy exposome: multiple environmental exposures in the INMA-Sabadell birth cohort. Environ Sci Technol. 2015;49(17):10632-41. https://doi.org/10. 1021/acs.est.5b01782.

62. Buck Louis GM, Schisterman E, Sweeney AM, Wilcosky TC, Gore-Langton RE, Lynch CD, et al. Designing prospective cohort studies for assessing reproductive and developmental toxicity during sensitive windows of human reproduction and development the LIFE study. Paediatric Perinatal Epidemiologyerinatal Epidemiology. 2011;25(5):413-24. https://doi.org/10.1038/mp. 2011.182.

63. Chung MK, Buck Louis GM, Kannan K, Patel CJ. Exposomewide association study of semen quality: systematic discovery of endocrine disrupting chemical biomarkers in fertility require large sample sizes. Environ Int. 2019;125(December 2018):505-14. https://doi.org/10.1016/j.envint.2018.11.037.

64. Chung MK, Kannan K, Louis GM, Patel CJ. Toward capturing the exposome: exposure biomarker variability and coexposure patterns in the shared environment. Environ Sci Technol. 2018;52(15):8801-10. https://doi.org/10.1021/acs.est.8b01467.

65. Janssen BG, Byun HM, Gyselaers W, Lefebvre W, Baccarelli AA, Nawrot TS. Placental mitochondrial methylation and exposure to airborne particulate matter in the early life environment: an ENVIRONAGE birth cohort study. Epigenetics. 2015;10(6): 536-44. https://doi.org/10.1080/15592294.2015.1048412.

66. Hoeke H, Roeder S, Bertsche T, Lehmann I, Borte M, von Bergen $\mathrm{M}$, et al. Monitoring of drug intake during pregnancy by questionnaires and LC-MS/MS drug urine screening: evaluation of both monitoring methods. Drug Test Analy. 2015;7(8):695-702. https://doi.org/10.1002/dta.1767.

67. North ML, Brook JR, Lee EY, Omana V, Daniel NM, Steacy LM, et al. The Kingston allergy birth cohort. Ann Allergy Asthma Immunol. 2017;118(4):465-73. https://doi.org/10.1016/j.anai. 2017.01.002.

68. Lee WC, Fisher M, Davis K, Arbuckle TE, Sinha SK. Identification of chemical mixtures to which Canadian pregnant women are exposed: the MIREC study. Environ Int. 2017;99: 321-30. https://doi.org/10.1016/j.envint.2016.12.015.

69. Sarigiannis D. Assessing the impact of hazardous waste on children's health: the exposome paradigm. Environ Res. 2017;158(July):531-41. https://doi.org/10.1016/j.envres.2017.06. 031.

70. Sarigiannis D, Karakitsios S. Addressing complexity of health impact assessment in industrially contaminated sites via the exposome paradigm. 2018;42:37-48. https://doi.org/10.19191/ EP18.5-6.S1.P037.086.

71. Plusquin M, Chadeau-Hyam M, Ghantous A, Alfano R, Bustamante M, Chatzi L, et al. DNA methylome marks of exposure to particulate matter at three time points in early life. Environ 
Sci Technol. 2018;52(9):5427-37. https://doi.org/10.1021/acs. est.7b06447.

72. Timmermans EJ, Lakerveld J, Beulens JWJ, Boomsma DI, Kramer SE, Oosterman M, et al. Cohort profile: the geoscience and health cohort consortium (GECCO) in the Netherlands. BMJ Open. 2018;8(6). https://doi.org/10.1136/bmjopen-2018-021597.

73. Andrianou XD, Van Der Lek C, Charisiadis P, Ioannou S, Fotopoulou KN, Papapanagiotou Z, et al. Mapping drinking water and quality of life aspects in urban settings: a proof-of-concept study on the application of the urban exposome framework. (August). 2018. https://doi.org/10.1101/401927.

74. Baker MG, Simpson CD, Lin YS, Shireman LM, Seixas N. The use of metabolomics to identify biological signatures of manganese exposure. Ann Work Expos Health. 2017;61(4):406-15. https://doi.org/10.1093/annweh/wxw032.

75. Chen C-K, Bruce M, Tyler L, Brown C, Garrett A, Goggins S, et al. Analysis of an environmental exposure health questionnaire in a metropolitan minority population utilizing logistic regression and support vector machines. J Health Care Poor Underserved. 2013;24(1A):153-71. https://doi.org/10.1353/hpu.2013.0046.

76. Cortéjade A, Kiss A, Cren C, Vulliet E, Buleté A. Development of an analytical method for the targeted screening and multi-residue quantification of environmental contaminants in urine by liquid chromatography coupled to high resolution mass spectrometry for evaluation of human exposures. Talanta. 2016;146:694-706. https://doi.org/10.1016/j.talanta.2015.06.038.

77. Ellis JK, Athersuch TJ, Thomas LDK, Teichert F, Pérez-Trujillo $\mathrm{M}$, Svendsen C, et al. Metabolic profiling detects early effects of environmental and lifestyle exposure to cadmium in a human population. BMC Med. 2012;10(1):61. https://doi.org/10.1186/17417015-10-61.

78. Fave M-J, Lamaze F, Hodgkinson A, Gauvin H, Bruat V, Grenier $\mathrm{J}-\mathrm{C}$, et al. Genomic and environmental contributions to chronic diseases in urban populations. BioRxiv. 2017:099770. https://doi. org/10.1101/099770.

79. Ferrreira APS d S, Pereira EC, Salles FJ, Silva FF d, Batista BL, Handakas E, et al. Home-based and informal work exposes the families to high levels of potentially toxic elements. Chemosphere. 2019;218:319-27. https://doi.org/10.1016/j.chemosphere.2018. 11.083 .

80. Garí M, Bosch C, Grimalt JO, Sunyer J. Impacts of atmospheric chlor-alkali factory emissions in surrounding populations. Environ Int. 2014;65:1-8. https://doi.org/10.1016/j.envint. 2013.12.008

81. Ge X, Wang F, Zhong Y, Lv Y, Jiang C, Zhou Y, et al. Manganese in blood cells as an exposure biomarker in manganese-exposed workers healthy cohort. J Trace Elem Med Biol. 2018;45(June 2017):41-7. https://doi.org/10.1016/j.jtemb.2017.09.016.

82. Gil AM, Duarte D, Pinto J, Barros AS. Assessing Exposome effects on pregnancy through urine metabolomics of a Portuguese (Estarreja) cohort. J Proteome Res. 2018;17(3):1278-89. https:// doi.org/10.1021/acs.jproteome.7b00878.

83. Lai Y, Xue J, Liu C-W, Gao B, Chi L, Tu P, et al. Serum metabolomics identifies altered bioenergetics, signaling cascades in parallel with exposome markers in Crohn's disease. Molecules. 2019;24(3):449. https://doi.org/10.3390/molecules24030449.

84. Lau C-HE, Siskos AP, Maitre L, Robinson O, Athersuch TJ, Want EJ, et al. Determinants of the urinary and serum metabolome in children from six European populations. BMC Med. 2018;16(1): 202. https://doi.org/10.1186/s12916-018-1190-8.

85. Mota MPG, Santos Z, Soares J, Pereira A, Fonseca S, Peixoto F, et al. Oxidative stress function in women over 40 years of age, considering their lifestyle. Front Endocrinol. 2017;8(MAR):1-6. https://doi.org/10.3389/fendo.2017.00048.

86. Pino A, Chiarotti F, Calamandrei G, Gotti A, Karakitsios S, Handakas E, et al. Human biomonitoring data analysis for metals in an Italian adolescents cohort: an exposome approach. Environ Res. 2017;159(February):344-54. https://doi.org/10.1016/j. envres.2017.08.012.

87. Tanase AM, Marchio A, Dumitrascu T, Dima S, Herlea V, Oprisan $\mathrm{G}$, et al. Mutation spectrum of hepatocellular carcinoma from eastern-European patients betrays the impact of a complex exposome. J Exp Sci Environ Epidemiol. 2015;25(3):256-63. https://doi.org/10.1038/jes.2014.16.

88. Walker DI, Uppal K, Zhang L, Vermeulen R, Smith M, Hu W, et al. High-resolution metabolomics of occupational exposure to trichloroethylene. Int J Epidemiol. 2016;45(5):1517-27. https://doi. org/10.1093/ije/dyw218.

89. Williams-DeVane CLR, Reif DM, Cohen Hubal E, Bushel PR, Hudgens EE, Gallagher JE, et al. Decision tree-based method for integrating gene expression, demographic, and clinical data to determine disease endotypes. BMC Syst Biol. 2013;7(1). https:// doi.org/10.1186/1752-0509-7-119.

90. Stiegel MA, Pleil JD, Sobus JR, Stevens T, Madden MC. Linking physiological parameters to perturbations in the human exposome: environmental exposures modify blood pressure and lung function via inflammatory cytokine pathway. J Toxicol Environ Health Part A. 2017;80(9):485-501. https://doi.org/10.1080/15287394. 2017.1330578.

91. van Veldhoven K, Kiss A, Keski-Rahkonen P, Robinot N, Scalbert A, Cullinan $\mathrm{P}$, et al. Impact of short-term traffic-related air pollution on the metabolome - results from two metabolome-wide experimental studies. Environ Int. 2019;123(November 2018):124 31. https://doi.org/10.1016/j.envint.2018.11.034.

92. Bisgaard H, Vissing NH, Carson CG, Bischoff AL, Følsgaard NV, Kreiner-Møller E, et al. Deep phenotyping of the unselected COPSAC2010 birth cohort study. Clin Exp Allergy. 2013;43(12):1384-94. https://doi.org/10.1111/cea.12213.

93. van Veldhoven K, Keski-Rahkonen P, Barupal DK, Villanueva CM, Font-Ribera L, Scalbert A, et al. Effects of exposure to water disinfection by-products in a swimming pool: a metabolome-wide association study. Environ Int. 2018a. https://doi.org/10.1016/j. envint.2017.11.017.

94. van Veldhoven K, Kiss A, Keski-Rahkonen P, Robinot N, Scalbert A, Cullinan P, et al. Plasma following inhalation of diesel emissions. J Breath Res. 2018b;30(9):1384-94. https://doi.org/10. 1080/15287394.2017.1330578.

95. Damialis A, Häring F, Gökkaya M, Rauer D, Reiger M, Bezold S, et al. Human exposure to airborne pollen and relationships with symptoms and immune responses: indoors versus outdoors, circadian patterns and meteorological effects in alpine and urban environments. Sci Total Environ. 2019;653:190-9. https://doi.org/10. 1016/j.scitotenv.2018.10.366.

96. Catinon M, Cavalin C, Chemarin C, Rio S, Roux E, Pecquet M, et al. Sarcoidosis , inorganic dust exposure and content of bronchoalveolar lavage fluid: the the MINASARC pilot study Sarcoidosis Vasculitis and Diffuse Lung Diseases. 2018; 35; 327-332

97. Shaw GM, Yang W, Roberts EM, Kegley SE, Stevenson DK, Carmichael SL, et al. Residential agricultural pesticide exposures and risks of spontaneous preterm birth. Epidemiology. 2018. https://doi.org/10.1097/EDE.0000000000000757.

98. Shen H, Xu W, Peng S, Scherb H, She J, Voigt K, et al. Pooling samples for "top-down" molecular exposomics research: the methodology. Environ Health. 2014;13(1). https://doi.org/10. 1186/1476-069X-13-8.

99. Zheng X, Aly NA, Zhou Y, Dupuis KT, Bilbao A, Paurus VL, et al. A structural examination and collision cross section database for over 500 metabolites and xenobiotics using drift tube ion mobility spectrometry. Chem Sci. 2017;8(11):7724-36. https://doi. org/10.1039/c7sc03464d. 
100. Balazard F, Le Fur S, Valtat $S$, Valleron AJ, Bougnères $P$, Thevenieau D, et al. Association of environmental markers with childhood type 1 diabetes mellitus revealed by a long questionnaire on early life exposures and lifestyle in a case-control study. BMC Public Health. 2016;16(1). https://doi.org/10.1186/s12889016-3690-9.

101. Fiorito G, Vlaanderen J, Polidoro S, Gulliver J, Galassi C, Ranzi A, et al. Oxidative stress and inflammation mediate the effect of air pollution on cardio- and cerebrovascular disease: a prospective study in nonsmokers. Environ Mol Mutagen. 2018. https://doi. org/10.1002/em.22153.

102. Maitre L, Fthenou E, Athersuch T, Coen M, Toledano MB, Holmes E, et al. Urinary metabolic profiles in early pregnancy are associated with preterm birth and fetal growth restriction in the Rhea mother-child cohort study. BMC Med. 2014;12(1):110 Retrieved from https://doi.org/10.1186/1741-7015-12-110,

103. Cifuentes P, Reichard J, Im W, Smith S, Colen C, Giurgescu C, et al. Application of the public health exposome framework to estimate phenotypes of resilience in a model Ohio African-American Women's cohort. J Urban Health. 2019;96:57-71. https://doi.org/ 10.1007/s11524-018-00338-w.

104. Kershenbaum AD, Langston MA, Levine RS, Saxton AM, Oyana TJ, Kilbourne BJ, et al. Exploration of preterm birth rates using the public health exposome database and computational analysis methods. Int J Environ Res Public Health. 2014;11(12):1234666. https://doi.org/10.3390/ijerph111212346.

105. Gil AM, Duarte D, Pinto J, Barros AS. Assessing Exposome effects on pregnancy through urine metabolomics of a Portuguese (Estarreja) cohort. J Proteome Res. 2018;17(3):1278-89. https:// doi.org/10.1021/acs.jproteome.7b00878.

106. Oyana TJ, Matthews-Juarez P, Cormier SA, Xu X, Juarez PD. Using an external exposome framework to examine pregnancyrelated morbidities and mortalities: implications for health disparities research. Int J Environ Res Public Health. 2015;13(1):1-14. https://doi.org/10.3390/ijerph13010013.

107. Patel CJ, Manrai AK. development of exposome correlation globes to map out environment-wide associations. 2014:231-42. https://doi.org/10.1142/9789814644730_0023.

108. Patel CJ, Manrai AK, Corona E, Kohane IS. Systematic correlation of environmental exposure and physiological and self-reported behaviour factors with leukocyte telomere length. Int $\mathrm{J}$ Epidemiol. 2017;46(1):44-56. https://doi.org/10.1093/ije/ dyw043.

109. Bonneterre V, Faisandier L, Bicout D, Bernardet C, Piollat J, Ameille J, et al. Programmed health surveillance and detection of emerging diseases in occupational health: contribution of the French national occupational disease surveillance and prevention network (RNV3P). Occup Environ Med. 2010;67(3):178-86. https://doi.org/10.1136/oem.2008.044610.

110. Andra SS, Austin C, Wright RO, Arora M. Reconstructing prenatal and early childhood exposure to multi-class organic chemicals using teeth: towards a retrospective temporal exposome; 2016b. https://doi.org/10.1016/j.envint.2015.05.010.

111. Bessonneau V, Pawliszyn J, Rappaport SM. The saliva exposome for monitoring of individuals' health trajectories. Environ Health Perspect. 2017;125(7):1-10. https://doi.org/10.1289/EHP1011.

112. Rappaport SM, Barupal DK, Wishart D, Vineis P, Scalbert A. The blood exposome and its role in discovering causes of disease supplemental material. Environ Health Perspect. 2014;122(8):76974. https://doi.org/10.1289/ehp.1308015.

113. Irimie AI, Braicu C, Cojocneanu R, Magdo L, Onaciu A, Ciocan $\mathrm{C}$, et al. Differential effect of smoking on gene expression in head and neck cancer patients. Int J Environ Res Public Health. 2018;15(7). https://doi.org/10.3390/ijerph15071558.

114. Grosdidier S, Ferrer A, Faner R, Piñero J, Roca J, Cosío B, et al. Network medicine analysis of COPD multimorbidities. Respir
Res. 2014;15(1):1-11. https://doi.org/10.1186/s12931-014-01114.

115. Mielke HW, Gonzales CR, Powell ET. Soil lead and children's blood lead disparities in pre- and post-hurricane Katrina New Orleans (USA). Int J Environ Res Public Health. 2017a. https:// doi.org/10.3390/ijerph14040407.

116. Mielke HW, Gonzales CR, Powell ET, Mielke PW. Spatiotemporal exposome dynamics of soil lead and children's blood lead pre- and ten years post-hurricane Katrina: Lead and other metals on public and private properties in the city of New Orleans, Louisiana, U.S.A. Environ Res. 2017b;155(December 2016):208-18. https://doi.org/10.1016/j.envres.2017.01.036.

117. Albanese S, Taiani MVE, De Vivo B, Lima A. An environmental epidemiological study based on the stream sediment geochemistry of the Salerno province (Campania region, southern Italy). J Geochem Explor. 2013;131(August):59-66. https://doi.org/10. 1016/j.gexplo.2013.04.002.

118. Andrianou XD, Charisiadis P, Makris KC. Coupling urinary trihalomethanes and metabolomic profiles of type II diabetes: a casecontrol study. J Proteome Res. 2017;16(8):2743-51. https://doi. org/10.1021/acs.jproteome.6b01061.

119. Golding J, Gregory S, Iles-Caven Y, Lingam R, Davis JM, Emmett $\mathrm{P}$, et al. Parental, prenatal, and neonatal associations with ball skills at age 8 using an exposome approach. J Child Neurol. 2014;29(10):1390-8. https://doi.org/10.1177/ 0883073814530501 .

120. Golding J, Gregory S, Iles-Caven Y, Nowicki S. The mid-childhood and adolescent antecedents of women's external locus of control orientation. Wellcome Open Res. 2017;2(July):53. https://doi.org/10.12688/wellcomeopenres.12052.1.

121. Nowicki S, Gregory S, Iles-Caven Y, Ellis G, Golding J. Early home-life antecedents of children's locus of control. Front Psychol. 2018;9(OCT):1-12. https://doi.org/10.3389/fpsyg.2018. 02032.

122. Steer CD, Bolton P, Golding J. Preconception and prenatal environmental factors associated with communication impairments in 9 year old children using an exposome-wide approach. PLoS ONE. 2015;10(3):1-26. https://doi.org/10.1371/journal.pone. 0118701.

123. Yang Q, Zhao Y, Qiu X, Zhang C, Li R, Qiao J. Association of serum levels of typical organic pollutants with polycystic ovary syndrome (PCOS): A case-control study. Hum Reprod. 2015. 30(8): 1964-1973.https://doi.org/10.1093/humrep/dev123.

124. Simpson CD, Baker MG, Shireman LM, Lin YS, Seixas N. The use of metabolomics to identify biological signatures of manganese exposure. Ann Work Expos Health. 2016. https://doi.org/10. 1093/annweh/wxw032.

125. Jain P, Vineis P, Liquet B, Vlaanderen J, Bodinier B, van Veldhoven $\mathrm{K}$, et al. A multivariate approach to investigate the combined biological effects of multiple exposures. J Epidemiol Community Health. 2018;72(7):564-71. https://doi.org/10.1136/ jech-2017-210061.

126. Pleil JD, Stiegel MA, Fent KW. Exploratory breath analyses for assessing toxic dermal exposures of firefighters during suppression of structural burns. J Breath Res. 2014;8(3). https://doi.org/ 10.1088/1752-7155/8/3/037107.

127. Pleil JD, Stiegel MA, Sobus JR. Breath biomarkers in environmental health science: exploring patterns in the human exposome. J Breath Res. 2011;5(4). https://doi.org/10.1088/1752-7155/5/4/ 046005.

128. Van Breda SGJ, Wilms LC, Gaj S, Jennen DGJ, Briedé JJ, Kleinjans JCS, et al. The exposome concept in a human nutrigenomics study: evaluating the impact of exposure to a complex mixture of phytochemicals using transcriptomics signatures. Mutagenesis. 2015;30(6):723-31. https://doi.org/10.1093/ mutage/gev008. 
129. Schisler JC, Ronnebaum SM, Madden M, Channell MM, Campen MJ, Willis MS. Plasma following inhalation of diesel emissions. 2016;27(5):272-80. https://doi.org/10.3109/08958378.2015. 1030481.

130. Vrijheid M, Slama R, Robinson O, Chatzi L, Coen M, van den Hazel P, et al. The human early-life exposome (HELIX): project rationale and design. Environ Health Perspect. 2014;122(6):535-44.
131. Vineis P, Chadeau-Hyam M, Gmuender H, Gulliver J, Herceg Z, Kleinjans $\mathrm{J}$, et al. The exposome in practice: design of the EXPOsOMICS project. Int J Hyg Environ Health. 2017. https:// doi.org/10.1016/j.ijheh.2016.08.001.

Publisher's Note Springer Nature remains neutral with regard to jurisdictional claims in published maps and institutional affiliations. 